\title{
PRÁTICAS DE EDUCAÇÃO AMBIENTAL EM UM CENTRO DE REFERÊNCIA EM ASSISTÊNCIA SOCIAL (CRAS)
}

\section{ENVIRONMENTAL EDUCATION PRACTICES IN A REFERENCE CENTER IN SOCIAL ASSISTANCE (CRAS)}

\author{
Gleide da Silva Gama Chiquetto* \\ ORCID: https://orcid.org/0000-0002-2037-4400 \\ Otávio Souza Ribeiro** \\ ORCID: https://orcid.org/0000-0003-3072-9751 \\ Ana Paula Silva Teles*** \\ ORCID: https://orcid.org/0000-0003-4689-0590 \\ Alexandra Sanae Maeda**** \\ ORCID: https://orcid.org/0000-0001-9358-9966 \\ Lucas Castro Torres***** \\ ORCID: https://orcid.org/0000-0001-9057-2122 \\ Francilina Araújo Costa****** \\ ORCID: https://orcid.org/0000-0002-2579-9125
}

\section{Resumo}

A educação ambiental visa despertar nas pessoas o cuidado com o ambiente, buscando assegurar seus direitos e responsabilidades para com o ambiente. Nas comunidades, a educação ambiental pode ser determinante para minimizar os impactos negativos decorrentes das ações antrópicas e promover a mudança de hábito. Nesse sentido, o Projeto de Extensão Educação Ambiental em Comunidades da Universidade Católica Dom Bosco (UCDB), em parceria com o Centro de Referência de Assistência Social Albino Coimbra Filho, realizou atividades abordando a educação ambiental, visando desenvolver competências e habilidades, para a conservação e uso consciente dos recursos naturais. As atividades desenvolvidas tiveram como públicoalvo a comunidade assistida pelo CRAS e a temática foi abordada através de oficinas, palestras, rodas de conversas, tardes de brincadeiras e a construção de um parquinho de recreação com pneus inservíveis. Tais ações contribuíram para reflexões sobre a necessidade de promover uma mudança de hábitos, além de aprimorar os valores ético-ambientais para o exercício da cidadania.

Palavras-chave: Aproveitamento de Resíduos Sólidos. Uso dos Recursos Ambientais. Reciclagem.

Data recebimento: $27 / 11 / 2020$

Data de aceite: $16 / 06 / 2021$

\begin{abstract}
Environmental Education aims to awaken people to care the environment, seeking to ensure their rights and responsibilities towards it. In the communities, environmental education may be a decisive factor to minimize the negative impacts of anthropic actions and to change habits. Thus, the outreach project Environmental Education in Communities carried out at Dom Bosco Catholic University (UCDB), in partnership with Albino Coimbra Filho Social Assistance Reference Center, conducted activities addressing environmental education to develop people's competences and skills for the conservation and the conscious use of natural resources. The activities had as target audience the community assisted by the Reference Center in Social Assistance (CRAS) and the theme was addressed through workshops, lectures, conversation circles, playful afternoons and the construction of a recreational park with recyclable tires. Such actions contributed to the reflections on the need to change habits, besides improving ethical and environmental values for citizens exercise their rights.
\end{abstract}

Keywords: Waste utilization; Use of environmental resources; Recycling. 


\section{Introdução}

O artigo 225 da Constituição Federal Brasileira de 1988 estabelece que todo cidadão brasileiro tem direito ao meio ambiente ecologicamente equilibrado, embora, na prática, esse direito não tenha sido garantido, sendo violado cotidianamente por decisões pessoais, políticas e econômicas, que desrespeitam o meio ambiente, bem de uso comum do povo e essencial à qualidade de vida de todos.

Desde a década de 1970, a educação ambiental é discutida no Brasil por meio de reuniões e conferências para deliberação de princípios, conceitos e objetivos para sua implantação, e após haver o desenvolvimento de suas diretrizes, passou a integrar os currículos educacionais com ressalva a sua implementação de maneira interdisciplinar, multidisciplinar e transversal (LIMA, 2015). Entretanto, a educação ambiental só foi introduzida de maneira formal em 1999 pela Lei da Política Nacional de Educação Ambiental, tornando-se, assim, o único país da América Latina a apresentar uma política específica para a educação ambiental (DIAS, 2010).

A educação ambiental é um processo dinâmico pelo qual as pessoas aprendem sobre o ambiente, a dependência dos organismos vivos, dos recursos naturais, como são afetados e como se promove a sua sustentabilidade. Na educação ambiental, deve-se levar em consideração os aspectos sociais, políticos, econômicos, científicos, tecnológicos, culturais, ecológicos e éticos, em que o indivíduo possa adquirir conhecimentos, valores, comportamentos e habilidades práticas para participar continuamente na solução de problemas ambientais como forma de melhoria da qualidade de vida, de forma a suscitar mudanças de posturas, atitudes, comportamentos e valores (DIAS, 2010; QUINTAS, 2008; PINOTTI, 2016).

Considerando ainda a questão ambiental, a Política Nacional de Educação Ambiental (PNEA), instituída pela Lei Federal n ${ }^{\circ}$ 9.795, de 27 de abril de 1999, estabelece que a educação ambiental é um componente essencial e permanente da educação nacional, devendo estar presente, de forma articulada, em todos os níveis e modalidades do processo educativo. Esta articulação pode ser tanto em caráter formal, quando inserida nos currículos das instituições de ensino em todos os níveis, quanto em caráter não formal, quando conduzida na forma de "ações e práticas educativas voltadas à sensibilização da coletividade sobre as questões ambientais e à sua organização e participação na defesa da qualidade do meio ambiente" (BRASIL, 1999). Cabe ao Poder Público incentivar a ampla participação das universidades, entre outras instituições, na formulação e execução de programas e atividades vinculadas à educação ambiental não formal (ABREU, 2013).

$\mathrm{O}$ abismo existente entre a riqueza e a pobreza geram diversos problemas ambientais, desta forma, a questão ambiental não diz respeito somente a esta área. As iniciativas de trabalhar com temas voltados a educação ambiental têm como objetivo fortalecer igualmente os direitos sociais e econômicos, acreditando que a educação, funcione como instrumento de inclusão social, e a educação ambiental, como espaço de interação entre a sociedade e o seu meio, onde promove reflexões e se buscam alternativas aos modelos de desenvolvimento socioambientais, podendo ser uma alavanca para minorar as desigualdades sociais existentes (TEIXEIRA, 2013).

De acordo com Nogueira e Souza (2019), a educação ambiental, se pautada na realidade local e promovida dentro das comunidades, torna-se um alicerce para que os próprios moradores 
em especial, e as futuras gerações se tornem capazes de desenvolver, planejar e superar problemas no ambiente em que vivem.

Neste sentido, destacam-se as ações, projetos e programas de extensão universitária, os quais devem promover a realimentação do processo de ensino-aprendizagem e contribuir com o desenvolvimento de pesquisas. As atividades devem proporcionar também a inclusão de parte da sociedade que vive em situação de vulnerabilidade social, sendo privada de seus direitos, e marginalizada quanto aos seus deveres, o que inclui suas responsabilidades com o meio ambiente (SOUSA et al., 2017).

O trabalho social sobre a questão ambiental, a partir da reflexão, da sensibilização e da difusão de conhecimentos, é uma possibilidade de intervenção transformadora, capaz de empoderar a comunidade para a busca por melhorias da qualidade ambiental do território e para o desenvolvimento de um modo de vida mais sustentável e saudável, contribuindo para o fortalecimento da autonomia e do sentimento de comunidade (BOLLA; MILIOLI, 2019).

Este artigo visa apresentar as atividades realizadas pelo projeto de extensão universitária "Educação Ambiental em Comunidades", em parceria com o Centro de Referência de Assistência Social (CRAS) Albino Coimbra Filho, no município de Campo Grande, Estado de Mato Grosso do Sul (MS). As atividades foram desenvolvidas ao longo de três anos, abordando a temática educação ambiental.

O CRAS é o equipamento responsável pela proteção básica e a execução do Serviço de Proteção e Atendimento Integral à Família (PAIF), que tem como objetivo apoiar as famílias, prevenindo a ruptura de laços, promovendo o acesso a direitos e contribuindo para a melhoria da qualidade de vida. $O$ trabalho consiste na realização, dentre outras intervenções, de oficinas com famílias, por meio das quais são discutidos os direitos humanos e os meios de acessá-los. Dentre esses direitos está o direito ao meio ambiente saudável (BRASIL, 2012).

As atividades realizadas no CRAS com a temática educação ambiental trabalham a consciência de que todo cidadão tem o direito ao meio ambiente saudável, além de serem oportunidades para reflexão sobre essa relação entre ser humano e natureza, permitindo o entendimento do ambiente e contribuindo para a promoção da sustentabilidade no âmbito local com ressonância global (PEREIRA; GUARESCHI, 2016).

O artigo apresenta o relato das ações experienciadas pelo Projeto de Extensão "Educação Ambiental em Comunidades", vinculado à Pró-Reitoria de Extensão e Graduação (PROGEX) da Universidade Católica Dom Bosco, desenvolvido durante um período de três anos consecutivos, no CRAS Albino Coimbra Filho, visando trabalhar questões de educação, conscientização, preservação ambiental e reciclagem de diversos resíduos. As ações do projeto objetivam também a mudança de hábitos, a geração de renda e formação de cidadãos conscientes que preservem o meio ambiente em que vivem e os recursos naturais. Por fim, a interação com a comunidade contribui com a preparação dos acadêmicos para o mercado de trabalho, promove a extensão universitária e estimula o exercício da cidadania. 


\section{Método}

No Município de Campo Grande/MS a assistência social tem como foco o atendimento às famílias com ações emancipatórias, voltadas ao enriquecimento do universo informacional, acesso aos bens e serviços sociais e participação social, preparando-as para superar as limitações pessoais de forma a conquistar a autonomia. O CRAS Dr. Albino Coimbra Filho, localizado no Bairro Jardim Aeroporto, foi criado em 16/08/2004 como Centro de Múltiplo Uso, transformou-se em Unidade Descentralizada de Assistência Social em 2004 e posteriormente em Centro de Referência de Assistência Social (CRAS) em 2005. O CRAS é uma unidade pública e estatal, que oferta serviços emergenciais e/ou continuados a famílias e indivíduos de vulnerabilidade social.

O CRAS Dr. Albino Coimbra Filho está localizado na "Região Urbana do Imbirussu", cuja população desta região é de 98.752 habitantes, dos quais 51.060 correspondem a mulheres e 47.692 a homens. Mais de 70\% da população encontra-se na faixa etária de 0 a 24 anos e cerca de $58 \%$ dos domicílios particulares permanentes possuem rendimento nominal mensal domiciliar per capita superior a $1 \frac{1}{2}$ até 2 salários-mínimos (CAMPO GRANDE, 2020). Trata-se de um espaço físico destinado à execução de ações integradas de Assistência Social da Prefeitura Municipal de Campo Grande, voltada para a melhoria da qualidade de vida da população que reside na região. Atende, além de adultos e idosos, crianças e adolescentes de faixa etária de 6 a 15 anos. Tem por foco a constituição de espaço de convivência, formação para a participação e cidadania, desenvolvimento do protagonismo e da autonomia das crianças e adolescentes, a partir dos interesses, demandas e potencialidades dessa faixa etária.

Para os adultos das diferentes faixas etárias, visa o desenvolvimento da autonomia e de sociabilidades, no fortalecimento dos vínculos familiares, do convívio comunitário, na prevenção de situações de risco social e demandas dessas faixas etárias, assim possibilitando o acesso dos seus usuários aos direitos de cidadania, contribuindo para melhoria da qualidade de vida dos usuários. Além disso, são desenvolvidas, com os idosos, atividades que contribuem no processo de envelhecimento saudável.

O Projeto de Extensão Educação Ambiental em Comunidades executou, ao longo de três anos (2017 a 2019), em parceria com o CRAS Albino Coimbra Filho, diversas atividades abordando a temática educação ambiental. O público-alvo era formado de pessoas em situação de pobreza e extrema pobreza que se encontram em vulnerabilidade e risco social, com fragilização dos vínculos familiares. Foram atendidos idosos, adultos, adolescentes entre 6 e15 anos e crianças, de ambos os sexos e com diferentes níveis de escolaridade e renda.

A execução e supervisão de cada atividade do projeto no CRAS Albino Coimbra Filho ficaram sob responsabilidade dos professores extensionistas pertencentes ao projeto. Cada acadêmico extensionista foi instruído e treinado pelos professores das diferentes áreas que abrangem a temática educação ambiental, fazendo com que estes tivessem condições de difundir os conhecimentos adquiridos à comunidade. Tendo em vista o caráter multidisciplinar $\mathrm{e}$ interprofissional do projeto, os extensionistas participantes eram acadêmicos dos cursos de Agronomia, Biologia e Engenharia Sanitária e Ambiental.

Os acadêmicos extensionistas foram estimulados a pesquisar os assuntos relacionados à temática educação ambiental - uso dos recursos naturais, consumo consciente, uso racional da 
água, alimentação saudável, resíduos sólidos, reciclagem e compostagem, entre outros. Em seguida, esses acadêmicos foram capacitados pelos professores extensionistas do projeto, que supervisionavam os mesmos na ministração de palestras educativas, oficinas e rodas de conversa.

As ações das oficinas aconteceram com o intuito de troca de conhecimentos e experiências entre os envolvidos - pessoas da comunidade, acadêmicos e professores. Foram realizadas várias oficinas dentro da temática ambiental, tais como produção de velas artesanais e sabão, utilizando óleo de cozinha usado, reciclagem de vidros e construção de jardineiras com garrafas PET para plantio de hortaliças e plantas medicinais em residências.

Antes do início das atividades, eram realizadas rodas de conversas e as discussões possibilitaram a percepção dos participantes em relação ao uso consciente dos recursos naturais, a preocupação com o ambiente e as práticas cotidianas visando a sustentabilidade e mudança de hábitos. A partir desta reflexão, eram apresentadas as possibilidades de reutilização e de reciclagem dentro das oficinas, a partir do uso de materiais alternativos, como garrafas PET, embalagens de vidro, caixas de leite e canos de PVC, que deram origem à produção de hortas suspensas, jardineiras e brinquedos.

Em outras atividades, a reciclagem foi exemplificada por meio de oficinas voltadas à produção de velas artesanais e sabão caseiro, a partir de óleo de cozinha usado e embalagens de vidro diversas. A produção de brinquedos recicláveis foi ministrada para os professores do CRAS para que, posteriormente, eles pudessem trabalhar com as crianças, orientando-as a construir seus próprios brinquedos. Foi realizado ainda um evento dentro da instituição, denominado "Tarde de Brincadeiras", em que os acadêmicos extensionistas confeccionaram brinquedos para as crianças e adolescentes pudessem utilizar ao longo deste período.

As temáticas abordadas, juntamente com o cronograma das atividades, eram elaboradas em conjunto entre os professores e acadêmicos extensionistas e equipe do CRAS Albino Coimbra Filho (coordenação e professores). No tempo dedicado às diferentes atividades (rodas de conversas, oficinas ou palestras), os acadêmicos extensionistas conduziam as atividades junto às crianças, supervisionados pelos professores extensionistas e professores do CRAS Albino Coimbra Filho. O mesmo procedimento era adotado quando o público-alvo eram os adultos e idosos, entretanto, a coordenadora do CRAS Albino Coimbra Filho se encarregava de divulgar e direcionar as pessoas que iriam participar das atividades.

Também com o apoio da coordenação foi construído um parquinho com pneus usados, de modo a proporcionar um espaço de recreação que ensinasse as crianças e adolescentes a importância da reciclagem. Ele foi construído com a ajuda das crianças da instituição para que pudessem dar a sua identidade ao ambiente, sentindo-se responsáveis pela sua construção, fazendo desenhos criativos nos muros e plantando flores dentro de pneus que serviram de jardineiras, além de participarem na produção dos brinquedos. 


\section{Resultados}

Desde o início da parceria com o CRAS Albino Coimbra Filho, procurou-se desenvolver atividades com temas voltados à Educação Ambiental, tendo como público-alvo a comunidade local, cujos atendidos eram pessoas em situação de pobreza e extrema pobreza e abrangendo uma faixa etária diversificada, desde crianças, adolescentes, jovens, adultos e idosos, com diferentes níveis de escolaridade. O CRAS Albino Coimbra Filho atende cerca de 145 crianças, nos períodos matutino e vespertino.

A programação foi dividida em dois momentos: o início, com uma apresentação teórica em forma de roda de conversa, cujo objetivo era dialogar com os participantes sobre os conceitos trabalhados na educação ambiental: 5Rs (repensar, recusar, reduzir, reutilizar e reciclar), consumo consciente, uso dos recursos ambientais, conservação ambiental, degradação da qualidade ambiental (poluição), dentre outros. No segundo momento, foram realizadas as oficinas e outras atividades práticas.

O Quadro 1 lista algumas das atividades realizadas, bem como a quantidade de participantes da comunidade envolvidos, totalizando 280 integrantes em 13 atividades. O segundo momento era dedicado à parte prática, com a produção de velas artesanais e sabão, utilizando óleo de cozinha usado.

Quadro 1 - Principais atividades realizadas no CRAS Albino Coimbra Filho

\begin{tabular}{|l|c|c|}
\hline \multicolumn{1}{|c|}{ Atividades } & $\begin{array}{c}\text { No de } \\
\text { atividades }\end{array}$ & $\begin{array}{c}\mathbf{N}^{\circ} \text { de } \\
\text { participantes }\end{array}$ \\
\hline $\begin{array}{l}\text { Oficina de jardineiras com garrafa PET para plantio de hortaliças e plantas } \\
\text { medicinais }\end{array}$ & 2 & 40 \\
\hline Oficina de produção de velas artesanais com óleo de cozinha usado & 4 & 80 \\
\hline Oficina de produção de sabão com óleo de cozinha usado & 1 & 20 \\
\hline Oficina de artesanato a partir da reciclagem do vidro & 3 & 50 \\
\hline $\begin{array}{l}\text { Oficina de confecção de brinquedos com materiais recicláveis (exclusivo para } \\
\text { professores do CRAS) }\end{array}$ & 1 & 10 \\
\hline Tarde da Brincadeira & 1 & 60 \\
\hline Construção de parquinho com pneus usados & 1 & 20 \\
\hline
\end{tabular}

Fonte: Elaborado pelos autores.

Uma vez que os acadêmicos extensionistas foram capacitados para as atividades propostas, foi possível perceber a relação dialógica com a comunidade, bem como o interesse de ambas as partes em compartilhar seus conhecimentos adquiridos a partir das experiências cotidianas, em sala de aula e em eventos de caráter técnico-científico. 
Na oficina de produção de velas artesanais (Figura 1) e sabão, foram trabalhados os conceitos de reutilização e reciclagem, enfatizando para os participantes que reutilizar e reciclar são ações que qualquer cidadão responsável pode e deve realizar para contribuir para o desenvolvimento sustentável. Os participantes puderam compreender que a reciclagem consiste na transformação de um resíduo em um produto com nova utilidade, como por exemplo o óleo usado de cozinha, que pode ser transformado para fazer vela, sabão e biocombustível.

Figura 1 - Oficina de confecção de velas artesanais a partir de óleo de cozinha usado para o público do CRAS

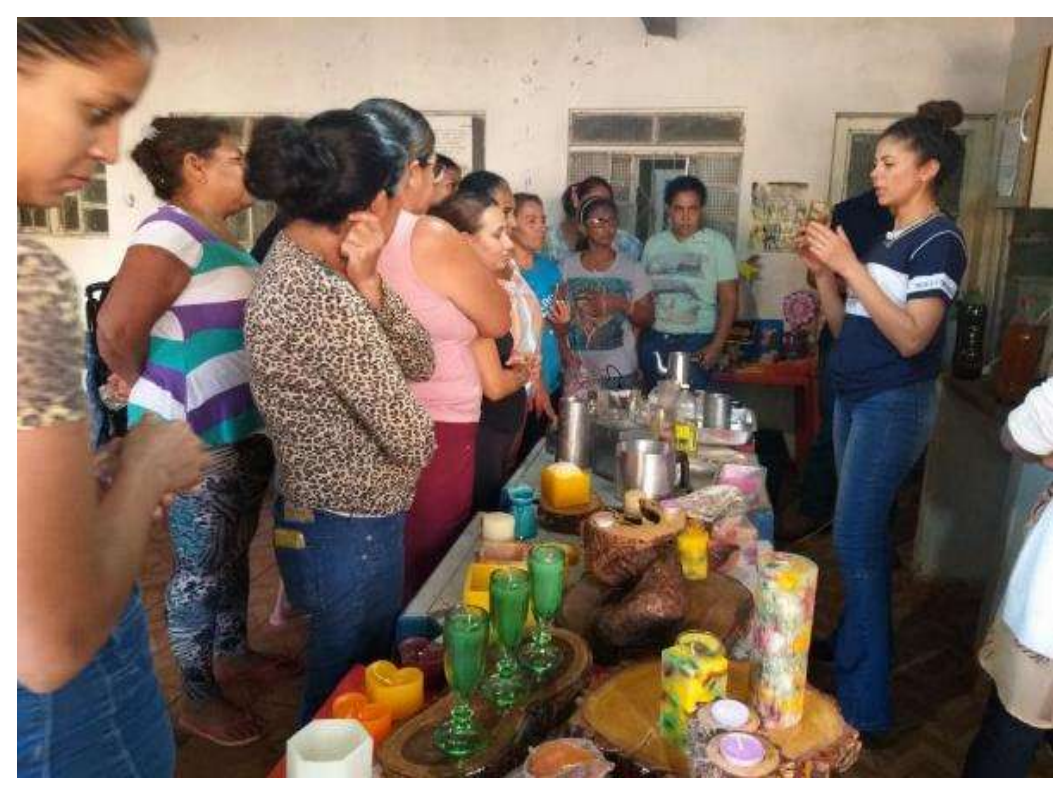

Fonte: Elaborado pelos autores.

O descarte inadequado dos resíduos sólidos urbanos ainda é um desafio às políticas públicas de gestão ambiental no Brasil. A reciclagem de resíduos surge como uma medida econômica, social e ambientalmente viável para se tentar reverter esse quadro (RIBEIRO et al., 2014). Além do benefício da transformação em um novo produto que pode ser comercializado para a geração de renda, a reciclagem reduz a poluição do ar, da água e do solo, além de diminuir a demanda por recursos ambientais e aumentar a vida útil dos aterros sanitários.

Outras oficinas foram destinadas aos resíduos plásticos e vidros, por meio de artesanatos a partir da reciclagem do vidro e a construção de jardineiras com garrafa PET, para plantio de hortaliças e plantas medicinais em residências. Como se trata de uma população carente procurou-se trabalhar com resíduos recicláveis comumente encontrados em ambiente doméstico ou de baixo custo e fácil aquisição. Em todas as atividades desenvolvidas, os participantes foram incentivados a reproduzirem as ideias em suas casas, possibilitando a geração de renda a partir dos produtos confeccionados por eles. 
Durante as oficinas, os produtos advindos das ações ficavam expostos e, ao final, era realizado um sorteio dentre os participantes, para presentear alguém com a produção do dia. Tendo em vista a facilidade de confecção dos produtos, as assistidas demonstravam bastante interesse em aprender durante a oficina para reproduzirem em suas casas. No encontro seguinte, algumas participantes compartilhavam sua produção por meio de fotos ou levando seus produtos finalizados.

As oficinas foram ministradas buscando configurar-se como uma atividade educativa, de forma lúdica, e de valorização das relações interpessoais e do trabalho artesanal. A partir dos comentários dos participantes ao longo das oficinas, foi possível perceber uma mudança na forma de ver os resíduos, bem como a visão diferente em relação à questão ambiental, a importância da conservação e uso sustentável dos recursos e do ambiente.

Os problemas ambientais estão mais presentes em ambientes cujas condições ambientais, sociais e econômicas são mais precárias, distinguindo um grupo social que não é atendido pelos benefícios dos investimentos públicos. Nesse contexto, os projetos na área de educação ambiental se tornam ferramentas importantes, visto os trabalhos realizados junto a essa parcela da população mais vulnerável, inclusive de conhecimentos e de oportunidades para mudança de realidades (MEDEIROS; SOUZA; FERREIRA, 2011).

A Educação Ambiental é um processo que busca a construção de conhecimentos voltados para a conservação do meio ambiente e procura instigar o ser humano a pensar em uma maneira ecologicamente correta de se viver. Ela visa despertar nos indivíduos o interesse de proteção, de forma a sensibilizá-lo, buscando garantir que todas as parcelas da sociedade, incluindo aquelas que vivem em condições vulneráveis, como crianças, adolescentes e donas de casas, não sejam privadas de seus direitos e que assumam suas responsabilidades com o meio ambiente (SOUSA et al., 2017).

Uma outra atividade, agora tendo como público-alvo os professores e auxiliares do CRAS Dr. Albino Coimbra Filho, foi a oficina de capacitação para a construção de brinquedos a partir de materiais recicláveis. Essa atividade objetivou que esses professores se tornassem multiplicadores desse aprendizado, ensinando as crianças assistidas a confeccionarem seus próprios brinquedos. Foi abordada como ideia central a saúde ambiental, visto que a reciclagem é fruto da preocupação com a qualidade de vida, aliada a um modelo de desenvolvimento responsável que preserve o meio ambiente.

A partir dessa reflexão introdutória, iniciou-se o segundo momento da atividade, que compreendeu basicamente demonstrar na prática como confeccionar os brinquedos. Foram feitos, juntamente com os professores, os brinquedos bilboquê, vai-e-vem, pescaria, boliche e jogos diversos (Figura 2). Após a confecção, foram realizadas brincadeiras entre os participantes, visando a integração e demonstrar na prática como as crianças se sentiriam diante dos brinquedos produzidos por elas mesmas. Ficou evidente o cumprimento do objetivo da oficina a partir dos relatos emocionantes das professoras, que relembraram seus momentos de criança e das brincadeiras. 
Figura 2 - Oficina de confecção de brinquedos a partir de materiais recicláveis com os professores

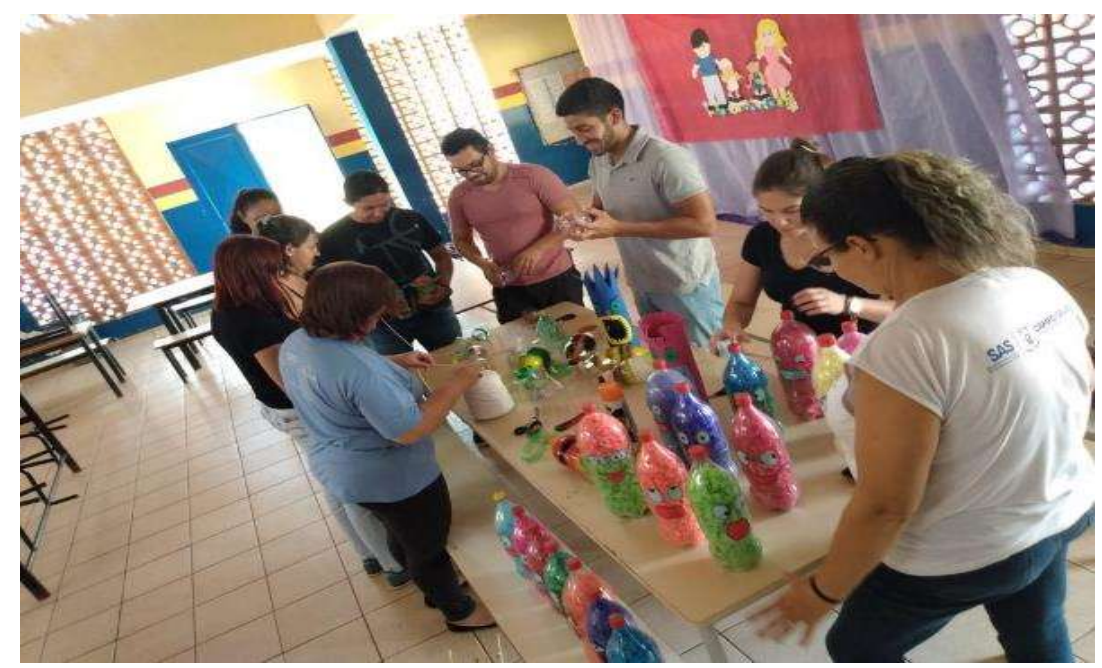

Fonte: Elaborado pelos autores.

Os resultados da oficina foram evidenciados e legitimados, por meio de várias manifestações de seus participantes, tais como: "Já vi esse brinquedo e sempre quis aprender a fazer ele"; "Vou aprender a fazer para ensinar e brincar aqui na escola e com meus filhos"; "Vou tentar produzir brinquedos e ao mesmo tempo buscar passar conhecimentos dentro de determinados assuntos", "Gostamos muito da oficina, voltem mais vezes". Os brinquedos confeccionados durante a oficina foram doados ao CRAS Dr. Albino Coimbra Filho para serem utilizados em outras atividades com as crianças.

Os educadores são importantes no processo de aprendizagem infantil, sendo fonte inesgotável de modelos e, por isso mesmo, é tão importante explicitar às crianças a intenção que está por trás de cada atitude e atividade realizada. Desta forma, para constituir hábitos de cuidado, preservação do meio ambiente e não desperdício dos recursos naturais, as crianças precisam encontrar no ambiente escolar e nas atitudes dos professores esses exemplos e ensinamentos (OLIVEIRA, 2012).

É necessário que todas as pessoas que atuam em instituições de ensino estejam preparadas para lidar com a educação ambiental, visto que essa deve ser desenvolvida de forma prática. Assim, é dever do educador, enquanto cidadão, formar pessoas com hábitos e comportamentos que venham a impedir que o meio ambiente, pela ação do próprio homem, torne-se inadequado para a vida saudável que se pretende deixar como legado às futuras gerações (TRAVASSOS, 2006).

Através da confecção de brinquedos a partir de materiais recicláveis, é possível trabalhar as potencialidades de cada criança, pôr à prova suas aptidões e testar seus limites. $\mathrm{O}$ ato de criar brinquedos com materiais recicláveis de diferentes naturezas permite às crianças descobrirem as diferentes propriedades e características dos resíduos sólidos. O brinquedo, em especial, é concebido como suporte da brincadeira, o material a ser reciclado torna-se brinquedo quando 
assume uma função lúdica, ou seja, quando a criança reveste esse material de um significado social, podendo agregar arte, educação, cultura e cidadania (SOUSA et al., 2017).

$\mathrm{Na}$ Educação Infantil, os trabalhos e as atividades voltadas a temas ambientais devem dar ênfase aos problemas ambientais e a aprendizagem deve ser contínua, demostrando os desafios e as soluções. Por meio das práticas ecologicamente corretas, é possível estimular a criatividade e ensinar para as crianças que podem ser reciclados diversos tipos de materiais, transformando-os em brinquedos e impedindo que esses venham a poluir o ambiente (DIAS, 2010).

Para que a educação ambiental no ensino infantil passe de possibilidades para uma realidade concreta a ser vivida nas escolas, é necessário estimular a preparação adequada do educador e a consolidação no ambiente escolar, com políticas educacionais e práticas educativas voltadas a essa temática e a materialização de um ambiente democrático aberto à participação coletiva de pais, alunos e equipe escolar (ALVES; SIMEÃO; RAMOS, 2016).

Além das oficinas, foi realizada uma atividade denominada "Tarde de Brincadeiras" (Figura 3) com as crianças do turno vespertino, fazendo uso somente de brinquedos construídos com materiais recicláveis, produzidos pelos acadêmicos extensionistas do projeto. Com essa atividade, pensamos em garantir que as crianças tenham oportunidades de novas brincadeiras quando se depararem com materiais recicláveis e que, também, aos poucos, elas sejam estimuladas a serem criativas e adquiram uma consciência ambiental, entendendo os problemas e as soluções, contribuindo assim para a formação de futuros cidadãos conscientes do seu papel na sociedade e nas questões ambientais. Participaram dessa atividade 60 crianças e adolescentes com idade entre 6 e 15 anos.

Figura 3 - Tarde da Brincadeira utilizando brinquedos feitos a partir de materiais recicláveis

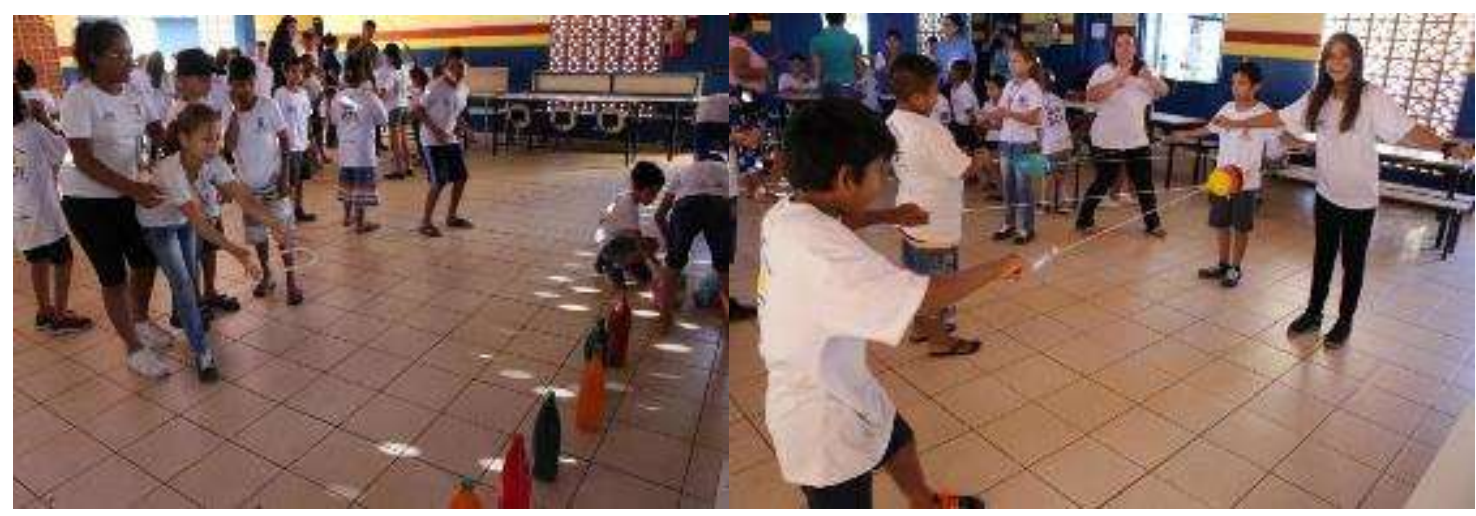

Fonte: Elaborado pelos autores.

De acordo com Sousa et al. (2017), a sociedade, além de buscar estratégias para promover a sensibilização ambiental dos indivíduos de modo geral, tem também o papel de proporcionar a inclusão social de pessoas mais desfavorecidas, sendo elas, frequentemente, esquecidas. As pessoas acolhidas nas casas institucionais têm, como qualquer cidadão brasileiro, direitos e deveres a serem cumpridos, incluindo os referentes ao meio ambiente, como previsto na Constituição 
Federal (BRASIL, 1988), sendo fundamental a participação neste processo das instituições de ensino superior, como as universidades, através de projetos de extensão.

No CRAS Dr. Albino Coimbra Filho, além das oficinas, o projeto pensou em como deixar nesta instituição algo definitivo que as crianças e adolescentes pudessem utilizar constantemente e se divertir, então foi construído um parquinho com pneus usados (Figura 4). Durante a sua confecção, foi possível contar com a participação das crianças e dos adolescentes da instituição, que auxiliaram na pintura dos pneus, no plantio de flores e na produção dos brinquedos, além de desenhos nos muros dos arredores, expressando toda a sua criatividade.

Foi um momento de muita descontração, em que puderam aprender na prática e de forma lúdica a importância de reciclar e de cuidar do meio ambiente. O parquinho foi inaugurado no Dia das Crianças, contando com a participação de toda comunidade circunvizinha ao bairro e de autoridades do município de Campo Grande - MS, beneficiando 145 crianças, dos períodos matutino e vespertino, no horário de recreio.

Figura 4 - Construção do parquinho com pneus usados

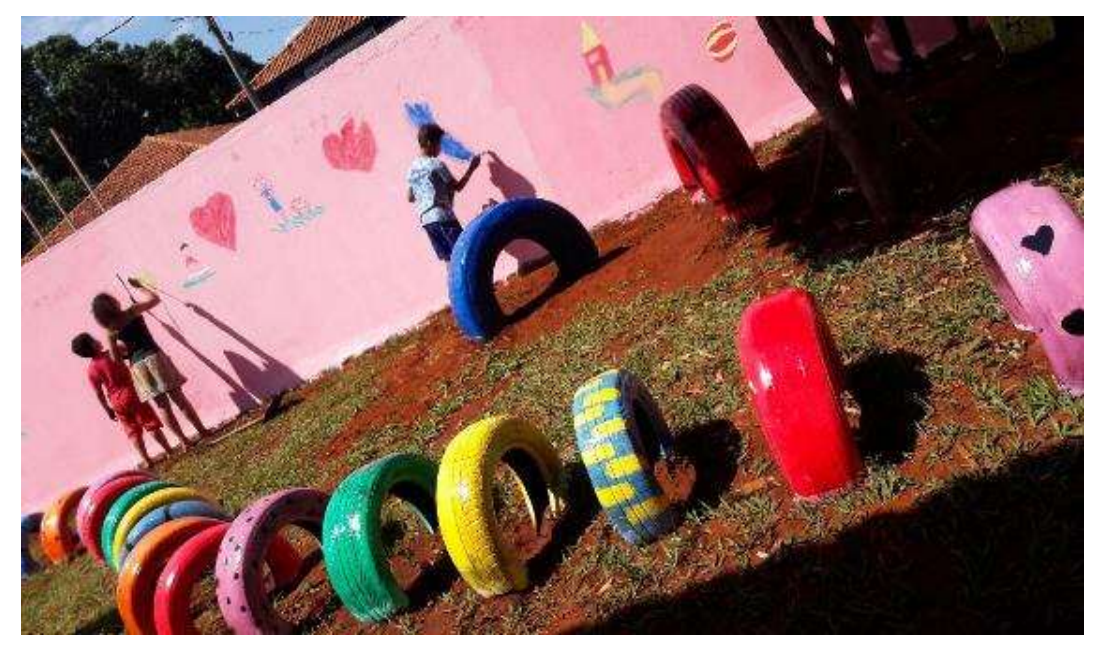

Fonte: Elaborado pelos autores.

Esta ação partiu do princípio de demonstrar para as crianças sobre as possibilidades do que se pode criar a partir de materiais recicláveis. Foi enfatizado para elas que nós podemos reaproveitar a maioria dos materiais que são descartados no ambiente de forma incorreta e que podemos utilizá-los de diferentes formas. Refletimos com as crianças sobre os problemas que podem ser causados pela destinação inadequada dos pneus, que, quando descartados de forma irregular no meio ambiente, tornam-se um problema devido às suas propriedades químicas, que dificultam a sua decomposição. Além disso, os pneus podem servir de abrigo para diversos animais sinantrópicos, que podem transmitir doenças e causar danos à saúde humana e animal.

No ambiente escolar, a educação ambiental deve buscar promover a conscientização do ser humano de uma forma geral e das crianças para práticas sustentáveis, sendo que esta 
educação deve se dar no início, ainda no ensino infantil, permitindo à criança possibilidades de sensibilização e reflexão sobre suas ações e possíveis consequências ao meio ambiente (ALVES; SIMEÃO; RAMOS, 2016).

\section{Conclusões}

Os integrantes do projeto, tanto professores como acadêmicos extensionistas, puderam compartilhar conhecimentos sobre assuntos relacionados à educação ambiental e conhecer, na prática, a realidade social dessa instituição e o cotidiano de acolhimento às pessoas em situação de vulnerabilidade social.

As expectativas do projeto foram atendidas, em função de se constatar o interesse e a participação da comunidade local nas diferentes atividades oferecidas, na busca por melhoria da qualidade de vida. No entanto, avalia-se que os resultados diretos das ações talvez possam ser mais perceptíveis no futuro do que no presente momento.

O projeto, através de suas ações, preocupou-se em contribuir com a realidade social, buscando trocar experiências sobre a reciclagem com produtos que pudessem proporcionar geração de renda, o que foi evidenciado pelo interesse e depoimento de alguns participantes após as oficinas ministradas, visto que esses passaram a produzir e comercializar produtos de materiais recicláveis.

\section{Referências}

ABREU, J. N. Educação Ambiental: Conceitos, Legislação, Decretos e Resoluções pertinentes e a formação continuada de professores em educação ambiental na Paraíba.

REMEA - Revista Eletrônica do Mestrado em Educação Ambiental, [S. 1.], v. 30, n. 1, p. 71-82, 2013.

ALVES, D. A.; SIMEÃO, E. M. S.; RAMOS, M. L. Educação ambiental na educação infantil: como e porque sua abordagem com crianças nessa faixa escolar. Colloquium Humanarum, Presidente Prudente, v. 13, n. Especial, p. 262-2679, jul-dez. 2016.

BOLLA, K. D. S.; MILIOLI, G. A Questão Ambiental no CRAS: Promoção de Qualidade de Vida e Sustentabilidade. Psicol. Cienc. Prof., Brasília, v. 39, e188719, 2019. 
BRASIL. Constituição da República Federativa do Brasil de 1988. Disponível em: http://www.planalto.gov.br/ccivil_03/constituicao/constituicao.htm. Acesso em: 07 nov. 2020.

BRASIL. Lei n ${ }^{\circ}$ 9.795, de 27 de abril de 1999. Dispõe sobre a educação ambiental, institui a Política Nacional de Educação Ambiental e dá outras providências. Diário Oficial da União, Disponível em: http://www.planalto.gov.br/ccivil_03/leis/19795.htm. Acesso em: 7 nov. 2020.

BRASIL. Ministério do Desenvolvimento Social e Combate à Fome. Secretaria Nacional de Assistência Social. Sistema Único de Assistência Social. Orientações Técnicas sobre o PAIF: Trabalho Social com Famílias do Serviço de Proteção e Atendimento Integral à Família - PAIF. v. 2. Brasília, 2012. Disponível em:

http://www.mds.gov.br/webarquivos/publicacao/assistencia_social/Cadernos/Orientacoes_P AIF_2.pdf. Acesso em: 17 fev. 2021.

CAMPO GRANDE. Agência Municipal de Meio Ambiente e Planejamento Urbano PLANURB. Perfil Socioeconômico de Campo Grande MS - EDIÇÃO 2020. 27 ed. rev. Campo Grande, 2020. Disponível em:

http://www.campogrande.ms.gov.br/planurb/downloads/perfil-socioeconomico-de-campogrande-ms-edicao-2020/. Acesso em 25 nov. 2020.

DIAS, G. F. Educação Ambiental: princípios e práticas. 9. ed. São Paulo: Gaia, 2010.

LIMA, G. P. Educação ambiental crítica: da concepção à prática. Revista Sergipana de Educação Ambiental, v. 2, n. 1, p. 33-54, 8 nov. 2015.

MEDEIROS, M. C. S.; SOUZA, C. A.; FERREIRA, C. M. A. Um estudo de caso no bairro São José, em João Pessoa-PB: impactos ambientais observados em comunidades carentes. In: Âmbito Jurídico, Rio Grande, XIV, n. 91, ago. 2011.

NOGUEIRA, M. DE N. L.; SOUZA, L. DE O. Educação Ambiental: um estudo de caso em uma comunidade ribeirinha do Estado do Amazonas. Ensino em Re-Vista, v. 26, n. 2, p. 320-344, 30 jun. 2019.

OLIVEIRA, Z. R. O trabalho do professor na educação infantil. São Paulo: Biruta, 2012.

PEREIRA, V. T.; GUARESCHI, P. A. O CRAS em relação: profissionais e usuários(as) em movimento. Fractal, Rev. Psicol., Rio de Janeiro, v. 28, n. 1, p. 102-110, Apr. 2016.

PINOTTI, R. Educação ambiental para o século XXI: no Brasil e no mundo [livro eletrônico]. São Paulo: Blucher, 2016. 
QUINTAS, J. S. A educação no processo de gestão ambiental. In: Educação Ambiental no Brasil. (salto para o futuro), Ano XVIII boletim 01, 2008.

RIBEIRO, L. C. S. et al. Aspectos econômicos e ambientais da reciclagem: um estudo exploratório nas cooperativas de catadores de material reciclável do Estado do Rio de Janeiro. Nova econ., Belo Horizonte, v. 24, n. 1, p. 191-214, Apr. 2014.

SOUSA, S. R.; ZORZAN, A. G.; VIANNA, P. C.; VIAN, C.; VISINTAINER, D. L. B.; POLLI, V. Práticas educativas no contexto ambiental em uma casa de acolhimento institucional do município de Passo Fundo. Revista Brasileira de Extensão Universitária, v. 8, n. 3, p. 175-183, 2017.

TEIXEIRA, L. A. Formação do educador ambiental: reflexões de um professor da escola pública. 2013. 276 f. Tese (doutorado) - Universidade Estadual Paulista Júlio de Mesquita Filho, Faculdade de Ciências de Bauru, 2013. Disponível em: http://hdl.handle.net/11449/102054. Acesso em: 10 maio 2021.

TRAVASSOS, E. G. A prática da educação ambiental nas escolas. Porto Alegre: Mediação, 2006. 